\title{
I 53 MR vessel wall imaging of the descending aorta using an elastin-binding contrast agent in an ApoE-/- TFDeltact double knockout mouse model of advanced atherosclerosis
}

\author{
Antti Saraste*1, Martina Knoedler ${ }^{1}$, Eliane Weidl ${ }^{1}$, Alexandra Keithahn ${ }^{1}$, \\ Marcus R Makowski ${ }^{1}$, Andreas Stein ${ }^{1}$, Simon Robinson ${ }^{2}$, Markus Schwaiger ${ }^{1}$, \\ Ilka Ott ${ }^{3}$ and Rene $M$ Botnar ${ }^{1}$
}

\author{
Address: ${ }^{1}$ Klinikum rechts der Isar, München, Germany, ${ }^{2}$ Bristol Myers Squibb, München, Germany and ${ }^{3}$ Deutsches Herzzentrum, München, \\ Germany \\ * Corresponding author
}

from I th Annual SCMR Scientific Sessions

Los Angeles, CA, USA. I-3 February 2008

Published: 22 October 2008

Journal of Cardiovascular Magnetic Resonance 2008, I0(SuppI I):A54 doi:I0.I I86/I532-429X-I0-SI-A54

This abstract is available from: http://jcmr-online.com/content/I0/SI/A54

(c) 2008 Saraste et al; licensee BioMed Central Ltd.

\section{Introduction}

A novel elastin-binding, Gadolinium-based low molecular weight contrast agent, BMS753951 (Bristol Myers Squibb, Billerica, MA) may be useful for visualization of the artery wall by delayed-enhancement magnetic resonance imaging (MRI). Synthesis and degradation of the extracellular matrix (ECM), including elastin, plays a central role in the natural progression of atherosclerosis. In particular, excessive ECM degradation in the advanced plaques has been suggested to be associated with plaque instability.

\section{Purpose}

Because elastin is involved in remodeling of the ECM in the atherosclerotic artery wall, we sought to study uptake patterns of BMS753951 in the thoracic and abdominal aorta of atherosclerotic mice by delayed-enhancement MR imaging.

\section{Methods}

Mice ageing 6 months lacking both apolipoprotein $\mathrm{E}$ and the cytoplasmic domain of tissue factor (ApoE- $-\mathrm{TF} \Delta \mathrm{ct}$ ) were fed on hypercholesteraemic diet for 3 months. Then MRI from the aortic bifurcation to the level of diaphragm was performed using a 1.5-T clinical scanner (Achieva, Philips Medical Systems, NL) equipped with a small sin- gle loop animal coil $(\varnothing=47 \mathrm{~mm})$. Course of the aortic lumen was displayed for the assessment of atherosclerotic narrowings and planning of the vessel wall scan on 3D time-of-flight (TOF) fast gradient echo angiography (field of view $30 \mathrm{~mm}$, matrix $100 \times 100$, in-plane resolution 0.3 mm, slice thickness $1 \mathrm{~mm}$, 32 slices, TR/TE 26/5 ms, flip angle 60 degrees) and coronal maximum intensity projections. Forty five minutes after injection of $0.2 \mathrm{mmol} / \mathrm{kg}$ of BMS75395, delayed-enhancement imaging using a 3D gradient echo inversion recovery sequence (field of view $35 \mathrm{~mm}$, matrix $292 \times 292$, in-plane resolution $0.12 \mathrm{~mm}$, slice thickness $1 \mathrm{~mm}$, 32 slices, TR/TE 37/10 ms, and flip angle 40 degrees) was performed to detect contrast uptake within the aortic vessel wall. The inversion time was adjusted to null blood by simulating plasma concentration of Gadolinium as a function of time (typically $\approx 300$ $\mathrm{ms}$ ). After the imaging experiment, animals were euthanized and aortas were collected for immunohistochemistry and examination of the elastin content. The extent of atherosclerotic lesions was analyzed by Sudan IV staining.

\section{Results}

Time-of-flight angiography showed significant luminal narrowing in the subrenal aorta when compared with the suprarenal aorta in all atherosclerotic mice. On average, the maximal luminal narrowing was $55 \pm 4.7 \%$. Contrast 


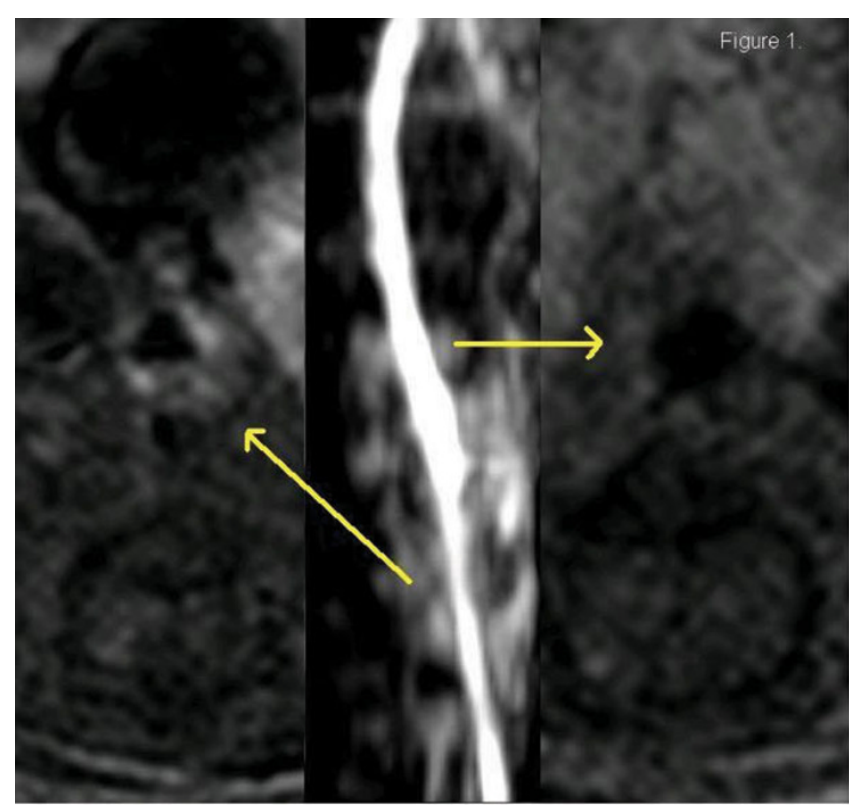

Figure I

Delayed-enhancement MRI demonstrated focal uptake of a novel gadolinium-based elastin-binding contrast agent in the atherosclerotic abdominal aorta of ApoE-/- TFct mice with little uptake in the non-stenotic suprarenal vessel segements.

uptake after injection of BMS753951 correlated well with sites of luminal narrowing and showed some slice-to-slice and intraplaque heterogeneity (Figure 1). Delayed enhancement was strongest at the luminal side of the investigated plaques. In the areas showing highest enhancement average contrast-to-noise ratio (CNR) between the vessel wall and aortic blood was $22.2 \pm 5.5$. Per cross section, average CNR between the vessel wall and aortic blood at the site of luminal narrowing was 3.1 times higher than in the suprarenal, non-stenosed aorta $(9.4 \pm 1.4$ vs. $3.0 \pm 1.0 ; \mathrm{p}<0.01$, Figure 2$)$.

\section{Conclusion}

Delayed-enhancement MRI demonstrates focal uptake of a novel gadolinium-based elastin-binding contrast agent in the atherosclerotic abdominal aorta of ApoE-/- TF $\Delta \mathrm{ct}$ mice with little uptake in the non-stenotic suprarenal vessel segements. In addition, contrast uptake appeared to co-localize with the fibrous cap and thus may be potentially useful for the detection of unstable plaques.

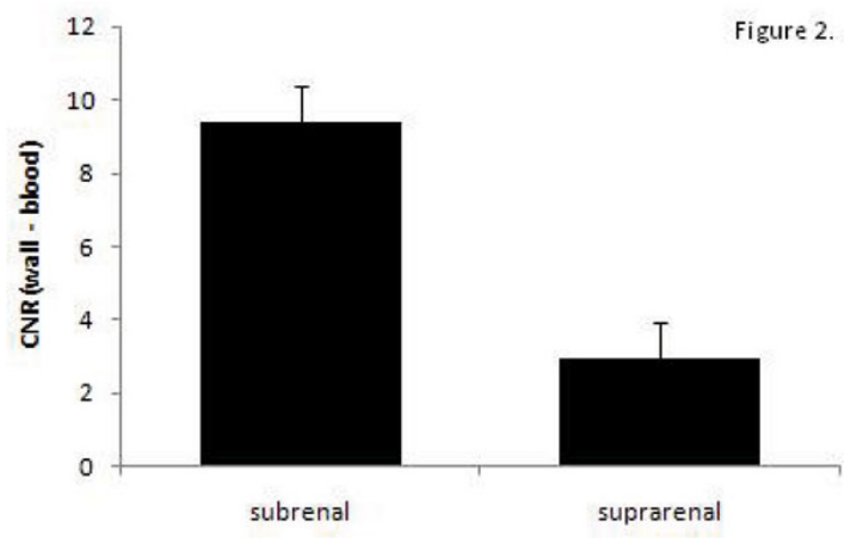

Figure 2

\footnotetext{
Publish with Biomed Central and every scientist can read your work free of charge

"BioMed Central will be the most significant development for disseminating the results of biomedical research in our lifetime." Sir Paul Nurse, Cancer Research UK

Your research papers will be:

- available free of charge to the entire biomedical community

- peer reviewed and published immediately upon acceptance

- cited in PubMed and archived on PubMed Central

- yours - you keep the copyright

Submit your manuscript here:

http://www.biomedcentral.com/info/publishing_adv.asp

BioMedcentral
} 